\title{
1 Role of the monocarboxylate transporter \\ 2 MCT1 in the uptake of lactate during active \\ 3 recovery
}

4 Rocío Cupeiro (1), Raúl Pérez-Prieto (2), Teresa Amigo (2,3), Pilar Gortázar (3),

5 Carlos Redondo (2), Domingo González-Lamuño $(2,3)$

61 LFE Research Group. Faculty of Physical Activity and Sports Sciences-INEF.

7 Universidad Politécnica de Madrid. Madrid, Spain.

8 C/Martín Fierro ${ }^{\circ} 7$, 28040, Madrid, Spain.

102 Laboratory of Pediatrics. School of Medicine. Universidad de Cantabria.

11 Santander, Spain

12 Facultad de Medicina. Universidad de Cantabria. Avda. Cardenal Herrera Oria

$13 s / n, 39011$, Santander, Cantabria, Spain

14

153 Division of Pediatrics. Valdecilla Research Institute (IDIVAL)

16 Edificio IDIVAL, Avenida Cardenal Herrera Oria s/n, 39011, Santander,

17 Cantabria, Spain

20 Correspondence To:

21 Rocío Cupeiro

22 E-mail: rocio.cupeiro@upm.es

23 Telephone number: +34913364070

24 Fax number: +34913364032 
2 Purpose: We assessed the role of monocarboxylate transporter 1 (MCT1) on lactate clearance

3 during an active recovery after high intensity exercise, by comparing genetic groups based on the

4 T1470A (rs1049434) MCT1 polymorphism, whose influence on lactate transport has been proven.

5 Methods: Sixteen young male elite field hockey players participated in this study. All of them

6 completed two $400 \mathrm{~m}$ maximal run tests performed on different days, followed by $40 \mathrm{~min}$ of active

7 or passive recovery. Lactate samples were measured immediately after the tests, and at min 10, 20,

830 and 40 of the recoveries. Blood lactate decreases were calculated for each $10 \mathrm{~min}$ period.

9 Participants were distributed into three groups according to the T1470A polymorphism (TT, TA

10 and AA). Results: TT group had a lower blood lactate decrease than AA group during the 10-20

11 min period of the active recovery $(\mathrm{p}=0.018)$. This period had the highest blood lactate for the

12 whole sample, significantly differing from the other periods $(\mathrm{p} \leq 0.003)$. During the passive

13 recovery, lactate declines were constant except for the 0-10 min period $(\mathrm{p} \leq 0.003)$, suggesting that

14 liver uptake is similar in all the genetic groups, and that the difference seen during the active

15 recovery is mainly due to muscle lactate uptake. Conclusions: These differences according to the

16 polymorphic variant T1470A suggest that MCT1 plays a central role-in taking up lactate from the

17 plasma to the muscle affects the plasma lactate decrease during a crucial period of active recovery,

18 where the maximal lactate amount is cleared (i.e. 10-20 min period).

20 Keywords: Monocarboxylate transporters, lactate clearance, active recovery.

22 Abbreviations: DNA: Deoxyribonucleic acid; MCT: Monocarboxylate transporter; PCR: 


\section{INTRODUCTION}

2 During exercise, oxidation by muscle and heart and gluconeogenesis by the liver

3 are the main fates for lactate (Bergman et al. 1999). Particularly, the oxidative

4 skeletal muscle contracting at submaximal intensity is the principal consumer

5 (Gladden 2004). This fact is reflected during low or moderate-intensity active

6 recovery, which has been proven to be efficient; increasing the blood lactate

7 clearance after high intensity exercise, especially during the first $20 \mathrm{~min}$. (Baker

8 and King 1991; Baldari et al. 2004; Menzies et al. 2010; Micklewright et al.

9 2006). Most of the membrane lactate transport (in symport with a proton) occurs

10 via a monocarboxylate transporter (MCT), with the MCT1 being the predominant

11 isoform in muscles (Fishbein et al. 2002; Pilegaard et al. 1999). The relevance of

12 MCT1 after high intensity exercise has already been reported by previous studies,

13 which found an association between MCT1 content and blood lactate removal or

14 blood lactate concentration (Green et al. 2002; Thomas et al. 2005). However,

15 these investigations used a passive recovery protocol, with a lower requirement

16 over MCT1 because resting muscles take less lactate due to a lower metabolic rate

17 (Brooks 2009; Gladden 2008; Miller et al. 2002). On the contrary, it would be

18 more relevant to investigate $\mathrm{MCT} 1$ and lactate clearance during active recovery,

19 in which lactate uptake by the muscles is increased (Miller et al. 2002). Moreover,

20 this type of recovery is a common situation during some training protocols, such

21 as high intensity interval training protocols, and during some sports, such as

22 intermittent team sports (Macutkiewicz and Sunderland 2011). Therefore, MCT1

23 is expected to have a relative importance during active recovery after high

24 intensity exercise. However, we do not know if its implication is constant over the

25 recovery or if it is more pronounced in a particular phase. 
1 The T1470A (rs1049434) polymorphism in the MCT1 gene (SLC16A1) is a

2 single-nucleotide polymorphism (SNP) (Lean and Lee 2009; Merezhinskaya et al.

3 2000) that has been related with sports performance and lactate transport (Ben-

4 Zaken et al. 2015; Cupeiro et al. 2010; Cupeiro et al. 2012; Fedotovskaya et al.

5 2014; Sawczuk et al. 2015), suggesting an impaired lactate transport in men

6 carrying the $\mathrm{T}$ allele. This reduced lactate transport associated with the SLC16A1

7 1470T allele has recently been confirmed by Sasaki et al., who found a lower

8 lactate uptake in oocytes expressing the wild type protein (i.e. the T allele) (Sasaki

9 et al. 2015). Thus, by comparing blood lactate concentrations of the different

10 genotype groups (TT, TA, AA) we aimed to assess the role of the MCT1 in blood

11 lactate clearance during an active recovery, proposing that a meaningful

12 involvement of MCT1 would be reflected on different lactate levels among 13 genetic groups.

14 We hypothesize that the main involvement of MCT1 occurs during the period of

15 maximal lactate clearance of the active recovery, that is, the first 20 minute-

16 period. In our study we investigated the role of the MCT1 on lactate removal

17 dynamics during an active recovery, using the T1470A (rs1049434) MCT1

18 genetic variant as a determinant of different functionality. Regarding the genotype

19 comparison of MCT1 isoforms, we hypothesize that the AA group has a greater

20 blood lactate clearance than the TT and TA groups during the active recovery,

21 while the three groups will have the same blood lactate decrease during the

22 passive recovery, reflecting the role of MCT1 on lactate uptake by the muscle. 


\section{Participants}

3 Sixteen healthy male field hockey players (age $21.7 \pm 2.7$ years, height $1.74 \pm$ $40.06 \mathrm{~m}$, body mass $70.0 \pm 6.3 \mathrm{~kg}$ ) of the same team competing in the highest 5 Spanish national level league participated in this study. We tested this sample

6 because it allowed an extensive control of diet and training. During the two years 7 prior to the data collection, these two factors were standardized and controlled.

8 Furthermore, all of the subjects were of the same Spanish (Caucasian) ancestry for

9 at least three generations. All principles outlined in the Declaration of Helsinki 10 were strictly followed. The design and performance of the research study was

11 described in the research protocol at the beginning of the study. All participants 12 signed an informed consent which includes: 1) the goal of the study; 2) a 13 statement for the unique use of the samples for the current study; and 3) explicit

14 anonymity about the final genetic result. The study was presented and approved 15 by an Academic Review board in the Department of Medical Sciences at the 16 University of Cantabria.

\section{Experimental procedure}

18 Participants performed two $400 \mathrm{~m}$ maximal run tests on a standard $400 \mathrm{~m}$ track, 19 each test followed by $40 \mathrm{~min}$ of an active or passive recovery, in the first and 20 second day, respectively. The active recovery involved $40 \mathrm{~min}$ of running at a 21 self-regulated intensity, which has proved to be suitable for lactate clearance 22 (Bonen and Belcastro 1976; Menzies et al. 2010). Subsequent analysis revealed 23 that this self-regulated intensity corresponded to $65 \%-75 \%$ of their age-predicted 24 maximal heart rate (Tanaka et al. 2001). The passive recovery consisted of sitting 25 for $40 \mathrm{~min}$. The participants were told to avoid any kind of exercise $24 \mathrm{~h}$ before 
1 the tests, which were separated by at least one recovery day. The experimental

2 protocol was double blinded in the sense that neither the evaluators nor the

3 subjects knew the genotype during the study.

\section{Lactate, heart rate and anthropometric measurements}

5 For measuring capillary lactate concentrations, blood samples from the fingertip

6 were obtained at rest before the $400 \mathrm{~m}$ run tests, immediately after finishing them

7 and four times during the recoveries: at $\min 10,20,30$ and 40 . These samples

8 were analyzed immediately after they were drawn using the Accusport portable

9 blood lactate analyzer (Boehringer Mannheim, Manheim, Germany), which has

10 been found to be valid and reliable (Bishop 2001; Pinnington and Dawson 2001).

11 Furthermore, only one device was used for all the measurements in order to avoid

12 potential error due to the use of different analyzers (Bishop 2001; Pinnington and

13 Dawson 2001).

14 Heart rate was recorded during all the trials and recoveries using a HR monitor

15 (Polar Electro, Kempele, Finland). Anthropometric measurements included height

16 and body mass using a balance with height attachment (Model 713, SECA,

17 Hamburg, Germany).

\section{Genotype assessment}

19 For the genetic analysis genomic DNA was extracted from peripheral blood using

20 a QIAamp DNA Blood Mini kit (Qiagen, Hilden, Germany). Genomic DNAs

21 from the participants were analyzed by polymerase chain reaction (PCR)

22 amplification of a fragment containing the T1470A polymorphism of the MCT1

23 gene (rs1049434, exon 5) and following direct sequencing. According with

24 Merezhinskaya et al. (Merezhinskaya et al. 2000) primers used for amplification 
1 were as follows: sense primer 5'-ACA CAT ACT GGG CAT GTG GC-3' (1455-

2 1474); antisense primer 5'-AAA TCC CAT CAA TGA ACA ACT GGT ATG

3 ATT TCC AC-3' (1807-1841). PCR reaction was made in a total volume of 50

$4 \mu \mathrm{L}$ containing: $3 \mu \mathrm{L}$ genomic DNA, $1.5 \mathrm{mM} \mathrm{MgCl} 2,0.2 \mathrm{mM}$ dNTP mix, $0.4 \mu \mathrm{M}$

5 primer, 4\% dimethyl sulfoxide (SIGMA, Sant Louis, MO, USA) and 1U Taq

6 polymerase (BioTaqPolimerase, Bio- Line, London, UK), using a GeneAmp ${ }^{\circledR}$

7 PCR System 2400 thermal cycler (Perkin Elmer, Applied Biosystems Division,

8 Foster City, CA, USA). The amplification consisted of initial denaturation $\left(94^{\circ} \mathrm{C}\right.$,

$95 \mathrm{~min}) ; 35$ cycles consisting of denaturation $\left(94^{\circ} \mathrm{C}, 1 \mathrm{~min}\right)$, annealing $\left(55^{\circ} \mathrm{C}, 1\right.$

$10 \mathrm{~min})$, and extension $\left(72{ }^{\circ} \mathrm{C}, 1 \mathrm{~min}\right)$; and final extension $\left(72{ }^{\circ} \mathrm{C}, 10 \mathrm{~min}\right) . \mathrm{PCR}$

11 products were electrophoresed in $1.5 \%$ agarose gel to verify successful

12 amplification of the $387 \mathrm{bp}$ fragments. Prior to sequencing, the PCR products

13 were purified using QIAquick PCR Purification Kit (Qiagen, Hilden, Germany).

14 The sequencing reactions were carried out using dRhodamine Terminator Cycle

15 Sequencing Kit (Applied Biosystems, Foster City, CA, USA) and analyzed on the

16 automated ABI Prism 310 Genetic Analyzer (Applied Biosystems). Gene

17 sequence of exon 5 was obtained from GeneBank (Accession: NM 003051).

\section{Data Analysis}

19 To analyze blood lactate clearance, we divided the 40 min recoveries into four

20 phases of $10 \mathrm{~min}$. Lactate removal during each $10 \mathrm{~min}$ period was calculated by

21 subtracting the blood lactate concentration at the beginning of the phase from the

22 blood lactate concentration-measured at the end of the phase. This calculation

23 reflected the blood lactate decrease in each defined period.

24 The statistical analysis was performed using the Statistical Package for the Social 25 Sciences software 21.0 (SPSS INC., Chicago, IL, USA) and the level of 
1 significance was set at 0.05 . To determine the normal distribution of the variables

2 we used a Shapiro-Wilk test and the Chi-square test was conducted to evaluate the

3 Hardy-Weinberg equilibrium. Given the sample size and the variables

4 distribution, non-parametric tests were used.

5 To assure both $400 \mathrm{~m}$ tests (active recovery test and passive recovery test) were

6 equally executed, in terms of performance and maximal effort and were different

7 in terms of recovery, a Wilcoxon test with Holm adjustment for multiple

8 comparisons was carried out with the entire sample and within each genotype

9 group. The variables for this analysis were time to complete the trials, heart rate

10 values and lactate concentrations measured throughout the tests, as well as the

11 lactate reductions during each $10 \mathrm{~min}$ phase of the recovery. Furthermore,

12 Friedman tests followed by Wilcoxon tests were used to compare the lactate

13 removed during the different 10 min phases within each recovery. On the other

14 hand, a Kruskal-Wallis test was used to compare anthropometric parameters and

15 age across genotypes, and to guarantee the equal performance of the tests among

16 genetic groups. Finally, we used a Friedman test to analyze differences in lactate

17 clearance phases across genetic groups. Data are presented as mean and standard

18 deviation (SD).

\section{RESULTS}

20 We did not experience any failure in the sample collection, DNA acquisition or

21 genotyping procedures. Genotype frequencies were $4(25.0 \%), 6(37.5 \%)$, and 6

$22(37.5 \%)$ for the TT, TA and AA genotypes respectively, being in accordance with

23 the Hardy-Weinberg equilibrium $\left(\chi^{2}=0.907, p=0.341\right)$. 
1 The Wilcoxon test comparing the two $400 \mathrm{~m}$ maximal run tests showed no

2 differences in time trial, maximal heart rate reached, basal lactate and lactate

3 concentration immediately after the test (Table 1). These parameters were also

4 similar among genetic groups, as well as the intensity of the active recovery

5 expressed by the percentage of their age-predicted maximal heart rate (data not

6 shown). We observed differences between active and passive recoveries in all the

7 lactate measurements (Table 1) and in all 10 min intervals $(p \leq 0.007)$, except for

8 the 20-30 min period. Within the passive recovery the rate of lactate removal was

9 constant over the 40 min except for the first $10 \min (\mathrm{p} \leq 0.003)$, since blood lactate

10 did not decrease during this period. On the other hand, during the active recovery

11 the highest decrease of blood lactate appeared in the $10-20 \min$ period $(5.6 \pm 1.1$

$12 \mathrm{mM} / \mathrm{L})$. This decrease significantly differed from the others $(p \leq 0.003)$, whereas

13 the lactate reduction for the $0-10 \mathrm{~min}$ period $(1.6 \pm 2.3 \mathrm{mM} / \mathrm{L})$ was similar to those

14 in the $20-30(2.0 \pm 1.3 \mathrm{mM} / \mathrm{L})$ and $30-40 \min$ periods $(0.4 \pm 0.5 \mathrm{mM} / \mathrm{L})$.

16 Table 1 about here

18 No differences were observed for anthropometric values or age across genotypes

19 (Table 2). Comparison of lactate concentrations among groups revealed no

20 differences, but the analysis of the lactate decreases reported a difference between

21 TT and AA groups in the 10-20 min period (Figure 1). During this phase (i.e. the

22 one with the maximum decrease of blood lactate) AA group exhibited a higher

23 lactate decrease than TT group. On the other hand, no differences were observed

24 for lactate concentrations or lactate decreases during the passive recovery. 
1 Table 2 about here

$3 \quad$ Figure 1 about here

4

\section{DISCUSSION}

6 Our main finding was the greater lactate reduction observed in the AA group

7 compared to TT group during the 10-20 min period of the active recovery, which

8 had the highest lactate clearance compared to the rest of the recovery periods

9 (active or passive). These results suggest a higher participation of MCT1 during

10 this period, reflecting the key role of MCT1 on high lactate transport rates.

11 The allele frequencies observed in our sample were similar to those seen in

12 previous studies with non-sedentary subjects (Ben-Zaken et al. 2015; Cupeiro et

13 al. 2010; Cupeiro et al. 2012; Sawczuk et al. 2015). An allelic frequency of 30\%-

$1435 \%$ for the $\mathrm{T}$ allele is commonly observed, especially in non-athletic populations

15 (Ben-Zaken et al. 2015; Merezhinskaya et al. 2000; Lean and Lee 2009; Sawczuk

16 et al. 2015). However, within athletic samples, the frequencies vary widely,

17 depending on the sport they perform (Fedotovskaya et al. 2014; González-Haro et

18 al. 2015; Sawczuk et al. 2015). These differences could be due to a sport

19 specialization (Ben-Zaken et al. 2015; Fedotovskaya et al. 2014; Sawczuk et al.

202015 ) or to an adaptive process of natural selection in populations and the neutral

21 processes of genetic drift in populations of different origin. Therefore, further

22 studies are necessary to conclude this observation. 
1 We observed a difference in blood lactate removal between genotypes according

2 to the T1470A MCT1 polymorphism, which alters lactate movement through this

3 transporter (Sasaki et al. 2015), only during the active recovery. Lactate uptake by

4 different organs involves both the MCT and the less efficient process of diffusion

5 (important at concentration $>2 \mathrm{mM} / \mathrm{L}$ ), thus it must be discussed if the

6 encountered differences could be due to the uptake by other organs, such as the

7 liver, expressing other MCT isoforms (Gladden 2008). Lactate removal by the

8 liver accounts for approximately $30 \%$ of total removal in resting humans

9 (Gladden, 2008) and no significant changes are reported after $40 \mathrm{~min}$ of low-

10 intensity exercise (Ahlborg, 1974). Consequently, we can assume that the role of

11 liver in active and passive recovery is similar. Therefore, the lack of differences

12 during the passive recovery among genetic groups implies that liver function is

13 similar in all the three groups, and that the difference we found is not due to liver

14 function but to muscle lactate uptake (i.e. the only condition that varies between

15 active and passive recoveries). Furthermore, this difference was only observed

16 from minute 10 to 20 of the recovery, suggesting that the transporter is especially

17 relevant during that period, where previous studies (Baker and King 1991;

18 Micklewright et al. 2006), as well as our results, locate the maximum rate of

19 blood lactate clearance. These results, alongside the fact that MCT1 is the

20 predominant isoform in oxidative skeletal fibers (Fishbein et al. 2002) and in

21 cardiac muscle (Gladden 2008), suggest that this transporter plays a central role in

22 taking up lactate from the plasma to the muscle exhibiting differences according 23 to the polymorphic variant T1470A. On the other hand, we did not find

24 differences in the other recovery periods (i.e. $\min 0-10,20-30$ and 30-40) maybe

25 because the reported blood lactate concentrations did not reach a minimal 26 threshold (approximately $10 \mathrm{mM} / \mathrm{L}$ ) to force the MCT1 polymorphic isoform, as 
1 previously hypothesized (Cupeiro et al. 2010; Cupeiro et al. 2012). Furthermore,

2 the first $10 \mathrm{~min}$ of the recovery, where lactate concentrations still remain high,

3 seems to be an adjustment phase where the blood lactate concentration depends on

4 multiple factors, including blood redistribution, buffer capacity or lactate efflux

5 from glycolytic fibers (Oyono-Enguelle et al. 1990).

6 Although these results should be taken with caution, since we did not evaluate

7 other factors influencing lactate removal (e.g. like mitochondrial oxidative

8 capacity or fiber type composition), our data suggests a key role of MCT1 in

9 lactate transport; especially during active recovery, when muscles are exercising

10 at low intensity and type I fibers are the most involved. Under these conditions,

11 MCT1 efficiency should be crucial, since a higher lactate transport would

12 increment the chance to use this metabolite as a substrate and an elevated proton

13 efflux from the muscle could prevent fatigue due to the proton gradient from

14 lactate producers to lactate consumers. Furthermore, we tried to limit the effect of

15 other factors on lactate removal selecting a very homogeneous sample in terms of

16 age, body composition and physical capacity, and controlling and standardizing

17 their training regime over two years.

18 Our data reflects significant differences in blood lactate clearance on subjects with

19 different efficiencies of MCT1 (i.e. AA and TT groups), observing a more

20 effective lactate take up in the AA genotype group. Trainers should consider this

21 fact for designing personalized recovery timings, both during training and

22 competition. Raising the efficiency of MCT1 must be a molecular target, in order

23 to modulate lactate and proton transport during recovery or low/moderate

24 intensity phases of competition; and therefore, not only improving energy

25 availability but also intracellular acid-base homeostasis. Further studies to extend 
1 the knowledge about the role of MCT1 during recovery are needed, especially for analyzing the involvement of the transporter in women, varying the intensity of

\section{ACKNOWLEDGEMENTS}

5 The authors thank Mr. N.K.E for his expert English writing advice.

\section{DISCLOSURES}

7 The authors have no conflicts of interest to disclose.

\section{REFERENCES}

9 Ahlborg G, Felig P, Hagenfeldt L, Hendler R, Wahren J (1974) Substrate turnover during

10 prolonged exercise in man: splanchnic and leg metabolism of glucose, free fatty acids, and amino

11 acids. J Clin Invest 53:1080-1090. doi: 10.1172/JCI107645

12 Baker SJ, King N (1991) Lactic acid recovery profiles following exhaustive arm exercise on a

13 canoeing ergometer. Br J Sports Med 25:165-167. doi: 10.1136/bjsm.25.3.165

14 Baldari C, Videira M, Madeira F, Sergio J, Guidetti L (2004) Lactate removal during active

15 recovery related to the individual anaerobic and ventilatory thresholds in soccer players. Eur J

16 Appl Physiol 93:224-230. doi: 10.1007/s00421-004-1203-5

17 Ben-Zaken S, Eliakim A, Nemet D, Rabinovich M, Kassem E, Meckel Y (2015) Differences in

18 MCT1 A1470T polymorphism prevalence between runners and swimmers. Scand J Med Sci

19 Sports 25:365-371. doi: 10.1111/sms.12226

20 Bergman BC, Wolfel EE, Butterfield GE, Lopaschuk GD, Casazza GA, Horning MA, Brooks GA

21 (1999) Active muscle and whole body lactate kinetics after endurance training in men. J Appl

22 Physiol 87:1684-1696.

23 Bishop D (2001) Evaluation of the Accusport ${ }^{\circledR}$ Lactate Analyser. Int J Sports Med 22:525-530.

24 doi: $10.1055 / \mathrm{s}-2001-17611$

25 Bonen A, Belcastro AN (1976) Comparison of self-selected recovery methods on lactic acid

26 removal rates. Med Sci Sports 8:176-178.

27 Brooks GA (2009) Cell-cell and intracellular lactate shuttles. J Physiol 587:5591-600. doi:

28 10.1113/jphysiol.2009.178350

29 Cupeiro R, Benito PJ, Maffulli N, Calderón FJ, González-Lamuño D (2010) MCT1 genetic

30 polymorphism influence in high intensity circuit training: A pilot study. J Sci Med Sport 13:526-

31 530. doi: 10.1016/j.jsams.2009.07.004

32 Cupeiro R, González-Lamuño D, Amigo T, Peinado AB, Ruiz JR, Ortega FB, Benito PJ (2012)

33 Influence of the MCT1-T1470A polymorphism (rs1049434) on blood lactate accumulation during 
1 different circuit weight trainings in men and women. J Sci Med Sport 15:541-547. doi:

2 10.1016/j.jsams.2012.03.009

3 Fedotovskaya ON, Mustafina LJ, Popov DV, Vinogradova OL, Ahmetov II (2014) A common

4 polymorphism of the mct1 gene and athletic performance. Int J Sports Physiol Perform 9:173-180.

5 doi: 10.1123/IJSPP.2013-0026

6 Fishbein WN, Merezhinskaya N, Foellmer JW (2002) Relative distribution of three major lactate

7 transporters in frozen human tissues and their localization in unfixed skeletal muscle. Muscle-and

8 Nerve 26:101-112. doi: 10.1002/mus.10168

9 Gladden LB (2004) Lactate metabolism: a new paradigm for the third millennium. J Physiol

10 558:5-30. doi: 10.1113/jphysiol.2003.058701

11 Gladden LB (2008) A “lactatic" perspective on metabolism. Med Sci Sport Exerc 40:477-485.

12 doi: 10.1249/MSS.0b013e31815fa580

13 González-Haro C, Soria M, Vicente J, Fanlo A, Sinués B, Escanero JF (2015) Variants of the

14 solute carrier SLC16A1 gene (MCT1) associated with metabolic responses during a long-graded

15 test in road cyclists. J Strength Cond Res 29:3494-3505. doi: 10.1519/JSC.0000000000000994

16 Green H, Halestrap A, Mockett C, O'Toole D, Grant S, Ouyang J (2002) Increases in muscle MCT

17 are associated with reductions in muscle lactate after a single exercise session in humans. Am J

18 Physiol Endocrinol Metab 282:E154-E160.

19 Lean CB, Lee EJD (2009) Genetic variations in the MCT1 (SLC16A1) gene in the Chinese

20 population of Singapore. Drug Metab Pharmacokinet 24:469-474. doi: 10.2133/dmpk.24.469

21 Macutkiewicz D, Sunderland C (2011) The use of GPS to evaluate activity profiles of elite women

22 hockey players during match-play. J Sports Sci 29:967-973. doi: 10.1080/02640414.2011.570774

23 Menzies P, Menzies C, McIntyre L, Paterson P, Wilson J, Kemi OJ (2010) Blood lactate clearance

24 during active recovery after an intense running bout depends on the intensity of the active

25 recovery. J Sports Sci 28:975-982. doi: 10.1080/02640414.2010.481721

26 Merezhinskaya N, Fishbein WN, Davis JI, Foellmer JW (2000) Mutations in MCT1 cDNA in

27 patients with symptomatic deficiency in lactate transport. Muscle and-Nerve 23:90-97. doi:

28 10.1002/(SICI)1097-4598(200001)23:1<90::AID-MUS12>3.0.CO;2-M

29 Micklewright DP, Sellens MH, Gladwell V, Beneke R (2006) Blood lactate removal using

30 combined massage and active recovery. Biol Sport 23:315-325.

31 Miller BF, Fattor JA, Jacobs KA, Horning MA, Navazio F, Lindinger MI, Brooks GA (2002)

32 Lactate and glucose interactions during rest and exercise in men: effect of exogenous lactate

33 infusion. J Physiol 544:963-975. doi: 10.1113/jphysiol.2002.027128

34 Oyono-Enguelle S, Marbach J, Heitz A, Ott C, Gartner M, Pape A, Vollmer JC, Freund H (1990)

35 Lactate removal ability and graded exercise in humans. J Appl Physiol 68:905-911.

36 Pilegaard H, Terzis G, Halestrap A, Juel C (1999) Distribution of the lactate/H+ transporter

37 isoforms MCT1 and MCT4 in human skeletal muscle. Am J Physiol 276:E843-848.

38 Pinnington H, Dawson B (2001) Examination of the validity and reliability of the Accusport blood

39 lactate analyser. J Sci Med Sport 4:129-138. doi: 10.1016/S1440-2440(01)80014-1

40 Robergs RA, Ghiasvand F, Parker D (2004) Biochemistry of exercise-induced metabolic acidosis.

41 AJP Regul Integr Comp Physiol 287:R502-R516. doi: 10.1152/ajpregu.00114.2004 
1 Sasaki S, Futagi Y, Kobayashi M, Ogura J, Iseki K (2015) Functional characterization of 5-

2 oxoproline transport via slc16a1/mct1. J Biol Chem 290:2303-2311. doi:

$3 \quad 10.1074 /$ jbc.M114.581892

4 Sawczuk M, Banting LK, Cięszczyk P, Maciejewska-Karłowska A, Zarębska A, Leońska-Duniec

5 A, Jastrzębski Z, Bishop DJ, Eynon N (2015) MCT1 A1470T: A novel polymorphism for sprint

6 performance? J Sci Med Sport 18:114-118. doi: 10.1016/j.jsams.2013.12.008

7 Tanaka H, Monahan KD, Seals DR (2001) Age-predicted maximal heart rate revisited. J Am Coll

8 Cardiol 37:153-156. doi: 10.1016/S0735-1097(00)01054-8

9 Thomas C, Perrey S, Lambert K, Hugon G, Mornet D, Mercier J (2005) Monocarboxylate

10 transporters, blood lactate removal after supramaximal exercise, and fatigue indexes in humans. J

11 Appl Physiol 98:804-809. doi: 10.1152/japplphysiol.01057.2004 
1

1 Figure 1. Rates of lactate clearance during the active recovery by genotype groups. * Significant 2 difference between TT and AA, $\mathrm{p}=0.018$. 
1 Table 1. Performance variables in both $400 \mathrm{~m}$ maximal run tests and lactate concentrations during

2 active and passive recoveries

\begin{tabular}{|c|c|c|c|}
\hline & Active recovery test & Passive recovery test & $\mathrm{p}$ \\
\hline Time (s) & $65.32(4.13)$ & $65.22(4.05)$ & 0.925 \\
\hline $\begin{array}{l}\text { Heart Rate at the end of the } 400 \\
m \text { run (bpm) }\end{array}$ & $1865.87(87.86)$ & $1843.71(87.67)$ & 0.454 \\
\hline Basal blood lactate (mM/L) & $1.4(0.4)$ & $1.4(0.3)$ & 0.975 \\
\hline $\begin{array}{l}\text { Blood lactate at the end of the } \\
400 \mathrm{~m} \text { run }(\mathrm{mM} / \mathrm{L})\end{array}$ & $11.2(2.5)$ & $11.0(2.2)$ & 0.552 \\
\hline $\begin{array}{l}\text { Blood lactate } 10 \mathrm{~min} \text { after the } \\
\text { end of the } 400 \mathrm{~m} \text { run }(\mathrm{mM} / \mathrm{L})\end{array}$ & $9.6(2.0)$ & $12.5(1.7)$ & 0.005 \\
\hline $\begin{array}{l}\text { Blood lactate } 20 \text { min after the } \\
\text { end of the } 400 \mathrm{~m} \text { run }(\mathrm{mM} / \mathrm{L})\end{array}$ & $4.0(1.7)$ & $9.7(1.6)$ & $<0.001$ \\
\hline $\begin{array}{l}\text { Blood lactate } 30 \mathrm{~min} \text { after the } \\
\text { end of the } 400 \mathrm{~m} \text { run }(\mathrm{mM} / \mathrm{L})\end{array}$ & $2.1(0.7)$ & $6.7(2.4)$ & $<0.001$ \\
\hline $\begin{array}{l}\text { Blood lactate } 40 \mathrm{~min} \text { after the } \\
\text { end of the } 400 \mathrm{~m} \text { run }(\mathrm{mM} / \mathrm{L})\end{array}$ & $1.7(0.5)$ & $4.9(1.4)$ & $<0.001$ \\
\hline
\end{tabular}

Values are presented as mean (SD). 
2 Table 2. Descriptive variables for the genotype groups.

\begin{tabular}{lllll}
\hline & TT $(\mathrm{n}=4)$ & TA $(\mathrm{n}=6)$ & AA $(\mathrm{n}=6)$ & $\mathrm{p}$ \\
\hline Age (years) & $21.5(4.0)$ & $20.8(1.2)$ & $22.7(3.0)$ & 0.612 \\
Height $(\mathrm{cm})$ & $173.5(3.7)$ & $175.4(8.2)$ & $173.7(5.2)$ & 0.963 \\
Weight $(\mathrm{kg})$ & $69.0(2.0)$ & $72.0(9.9)$ & $68.7(3.1)$ & 0.998
\end{tabular}

Values are presented as mean (SD). There were no statistical differences among genetic groups. 


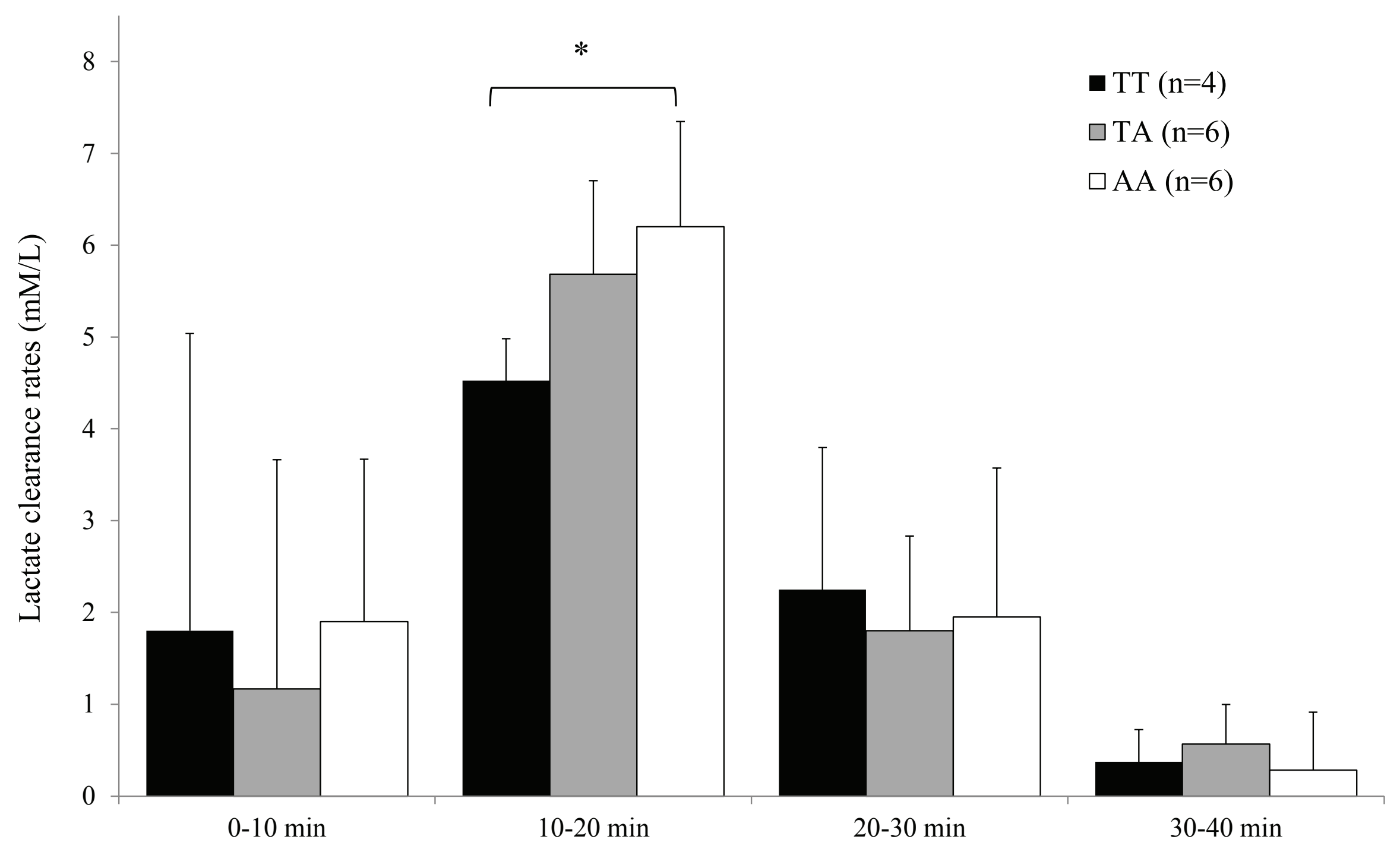

